\title{
Aspectos anatômicos do embrião e desenvolvimento inicial de Oenocarpus minor Mart.: uma palmeira da Amazônia ${ }^{1}$
}

\author{
Andréia Barroncas de Oliveira ${ }^{2,5}$, Maria Silvia de Mendonça ${ }^{3}$ e Maria Gracimar Pacheco de Araújo ${ }^{4}$
}

Recebido em 3/3/2008. Aceito em 9/12/2008

\begin{abstract}
RESUMO - (Aspectos anatômicos do embrião e desenvolvimento inicial de Oenocarpus minor Mart.: Uma palmeira da Amazônia). Neste trabalho foi feita a anatomia do embrião e a fase inicial da germinação da semente de $O$. minor. Frutos maduros de cinco indivíduos foram despolpados e as sementes obtidas foram semeadas em canteiros contendo substrato areia em casa de vegetação com sombreamento a $50 \%$. O acompanhamento da germinação foi feito através de coletas das diferentes fases do desenvolvimento. O estudo anatômico foi realizado conforme técnicas usuais de microscopia de luz. O embrião é capitado. O eixo embrionário localiza-se na região proximal em posição oblíqua ao eixo cotiledonar. O cotilédone é formado por tecido parenquimático, procambial e protodérmico. Os feixes vasculares ocorrem ao longo da zona periférica da região distal até ao eixo embrionário. Aos 14 dias é emitida a raiz primária. Aos 21 dias forma-se a primeira bainha cotiledonar e aos 35 dias a segunda bainha cotiledonar ocorrendo à emergência da plântula acima do substrato. A germinação é do tipo adjacente ligular.
\end{abstract}

Palavras-chave: anatomia, Arecaceae, bacabinha, germinação

ABSTRACT - (Anatomical aspects of the embryo and initial development of Oenocarpus minor Mart.: a palm tree from the Amazon). The anatomy of the embryo and the initial germination phase of $O$. minor seeds are examined here. Ripe fruits were collected from five individuals, the pulp removed, and the seeds sown in beds with sandy substrate in a greenhouse with $50 \%$ shade. Germination follow-up was made by collecting different stages of development. The anatomical study done according to usual techniques of light microscopy. The embryo is capitate and occupies a central position in the basal region of the seed. The embryogenic axis is located in the proximal region in a position that is oblique to the cotyledon axis. The cotyledon is formed by parenchymatous, procambial and protodermic tissue. The vascular bundles lie along the peripheral zone of the distal region to the embryogenicaxis. After 14 days, the primary rootemerges; after 21 days, the first cotyledon sheath and after 35 days, the second cotyledon sheath, and the seedling emerges above the substrate. Germination is of the ligule adjacent type.

Key words: anatomy, Arecaceae, "bacabinha", germination

\section{Introdução}

Nas florestas tropicais há uma grande diversidade e abundância de palmeiras, sendo reconhecida por Uhl \& Dransfield (1987) cerca de 2.500 a 3.500 espécies, distribuídas em 210 a 236 gêneros. Esse grupo de plantas encontra-se intimamente relacionada com a fauna e a flora regional, interagindo com o meio em que vivem de forma direta e indireta, seja servindo de sombreamento para pequenas populações de plântulas ou de alimentação para os animais.

As palmeiras são amplamente utilizadas pelas comunidades ribeirinhas residente nas imediações da floresta, sendo de uso as partes vegetativas e reprodutivas. Balick $(1986 ; 1992)$ descreve o auto-aproveitamento do gênero Oenocarpus, o que ressalta a importância deste para a economia de subsistência de vários povos neotropicais, índios e agricultores.

Estudos científicos com a família Arecaceae vêm sendo desenvolvidos na diferentes linhas de pesquisa, como na morfologia, na germinação, nos aspectos ecológicos, em sistemas agroflorestais, na etnobotânica, (Mendonça \& Araújo 1999; Araújo et al. 2000; Aguiar \& Mendonça 2003; Barcelar-Lima et al. 2006; Pivetta et al. 2008; Luz et al. 2008). Especificamente em anatomia, Passos \& Mendonça (2006) caracterizaram a epiderme foliar de Mauritia flexuosa L. f. e Mendonça et al. (2008) descreveram a morfo-anatomia do fruto e semente de Oenocarpus minor, a espécie em questão.
Entretanto, ainda do ponto de vista anatômico, com exceção de algumas espécies de importância comercial, pouco se conhece sobre a germinação de Palmeiras. Assim, informações nessa área do conhecimento, em especial de O. minor, possibilitarão a domesticação de espécies nativas que apresentam potencial econômico. O presente trabalho visou caracterizar anatomicamente o embrião e a fase inicial da germinação da semente de Oenocarpus minor Mart., conhecida popularmente como bacabinha.

\section{Material e métodos}

Frutos maduros de Oenocarpus minor Mart. foram coletados de cinco indivíduos, retirados de cada cacho, aleatoriamente, em área sob manejo florestal sustentado na Empresa Madeireira Itacoatiara Ltda, no município de Itacoatiara, Amazonas, com latitude $3^{\circ} 8$ ` $54^{\prime \prime}$ Sul e longitude $58^{\circ} 25^{\prime}$ Oeste.

De uma amostra de 350 sementes obtidas através de despolpamento manual dos frutos, 50 sementes foram destinadas para retirada dos embriões para análise anatômica e 300 sementes foram submetidas a uma préembebição em água por 24 horas, antes da semeadura (Marcus \& Banks 1999), sem nenhum tratamento asséptico, para serem acompanhadas as fases iniciais da germinação e posterior descrição anatômica.

No viveiro do Projeto Frutíferas da Universidade Federal do Amazonas, as 300 sementes embebidas foram postas para germinar em canteiros com $2 \mathrm{~cm}$ de profundidade, com espaçamento de $5 \mathrm{~cm}$ e sombreamento a $50 \%$, contendo substrato de areia. Em visitas diárias, o canteiro foi molhado manualmente com regador, geralmente pelo período da manhã, e observado o processo germinativo das sementes até a sua emergência. O percentual da germinação foi determinado com o aparecimento do botão germinativo e calculado por meio da seguinte fórmula: $(\mathrm{NSG} / \mathrm{NSS}) * 100$, onde $\mathrm{NSG}=$

\footnotetext{
Parte da Monografia da primeira Autora

Instituto Nacional de Pesquisas da Amazônia, Departamento de Botânica, Programa de Pós-Graduação em Botânica, Manaus, AM, Brasil

3 Universidade Federal do Amazonas, Faculdade de Ciências Agrárias, Departamento de Ciências Fundamentais Agrícola, Manaus, AM, Brasil

4 Universidade Federal do Amazonas, Departamento de Biologia, Manaus, AM, Brasil

Autor para correspondência: andreiabo@hotmail.com
} 
número de sementes germinadas; NSS= número de sementes semeadas (Callegari-Jacques 2003). As coletas foram feitas a cada sete dias, iniciandose sete dias após a semeadura e terminando com a sua emergência.

Para o estudo anatômico o material botânico coletado (embrião da semente madura e fases iniciais da germinação das sementes) foi imediatamente fixado em formaldeído, álcool etílico a $50 \%$ e ácido acético (FAA50), segundo Kraus \& Arduin (1997). Amostras das várias fases de germinação foram desidratadas em série alcoólica/butílica, incluída em parafina e seccionada em micrótomo rotativo. As secções histológicas foram coradas com azul de astra e safranina, ambos em solução aquosa (Kraus \& Arduin 1997) e montada em bálsamo do Canadá (Patiño 1986). Para o embrião, amostras foram desidratadas em série etílica (70\%-95\%), incluídas em 2-hidroxietil-metacrilato (Historesin Leica, preparada conforme as instruções do fabricante), seccionado em micrótomo rotativo, corados com azul de toluidina em pH 4,4 (O'brien \& Maccully 1981) e montados com resina sintética (Pemount-Fisher).

Teste histoquímico foi realizado, utilizando-se cortes transversais de amostra fresca do embrião, submetendo-o ao reagente dicromato de potássio a 10\% para composto fenólico (Gabe 1968).

O material estudado foi fotografado em máquina fotográfica digital SONY e estereoscópio ZEISS acoplado a câmera MC-80 DX e a câmera digital power shot A-620 CANON.

\section{Resultados e discussão}

Embrião - Oenocarpus minor possui embrião capitado conforme classificação de Martin (1946), distinguindo-se duas regiões: a região proximal, voltada ao poro germinativo de cor amarelo-pálida e a região distal de cor amarelo-clara (Mendonça et al. 2008). Mendonça \& Araújo (1999) também verificaram duas regiões distintas no embrião de Oenocarpus bacaba Mart. denominando-as de apical-periférica, que corresponde ao pecíolo cotiledonar, envolvendo o eixo embrionário e basal interna, que corresponde ao limbo cotiledonar o qual se transformará em haustório.

O embrião está localizado em posição central na região basal da semente, medindo em média $9 \mathrm{~mm}$ de comprimento e $4 \mathrm{~mm}$ de diâmetro (Mendonça et al. 2008). Podendo ser considerado relativamente grande quando comparado com embriões de outras espécies, que apresentam tamanhos menores, como em Euterpe precatoria Mart. (Aguiar \& Mendonça 2003) e Leopoldinia pulchra Mart. (M.G.P. Araújo, dados não publicados).

O embrião apresenta um cotilédone e um eixo embrionário (Fig. 1.1). O cotilédone é revestido por protoderme unisseriada com células variando de quadrada à retangular e núcleos evidentes e o limbo cotiledonar na sua maioria por tecido parenquimático com células de tamanhos e formatos variados (Fig. 1.2). A mesma variação de tamanho das células foi observada no embrião de Washingtonia filifera (Demason 1988).

Células multisseriadas (2-10) com ráfides inclusas e células com composto fenólico encontram-se circundando a região plumular, possivelmente atuando na proteção do eixo embrionário (Fig. 1.1-3). Também observadas na região proximal do embrião de Cocos nucifera Linn. (Sugimura \& Murakami 1990).

O eixo embrionário está localizado na região proximal em posição oblíqua ao eixo cotiledonar. É formado por plúmula (primórdios foliares) e pólo radicular. No gênero
Caryota, Ginieis (1956) denomina-os, respectivamente, como gêmula e radícula e Aguiar \& Mendonça (2002) em Euterpe precatoria como pólo caulinar e pólo radicular.

A plúmula (primórdios foliares) distinta em duas bainhas cotiledonares e eófilo (Fig. 1.3) são formadas por células indiferenciadas, revestidas por uma protoderme externa e interna, alojada no interior da cavidade cotiledonar. Tais observações são semelhantes ao descrito por Belin \& Queiroz (1988) e Aguiar \& Mendonça (2002) nas espécies Euterpe edulis Mart. e Euterpe oleracea Mart.

Opostamente à plúmula encontra-se um grupo de células meristemáticas que dará origem ao pólo radicular, também descrito para o embrião de Cocos nucifera por Sugimura \& Murakami (1990).

Os feixes procambiais são observados ao longo do cotilédone, em corte longitudinal (Fig. 1.4) na região periférica e em corte transversal estão ordenados formando um anel com cerca de 10 feixes (Fig. 1.5).

A região distal do embrião funcionará posteriormente como um órgão de sucção denominado haustório (Fig. 1.6) ou região haustorial, que irá digerir os nutrientes do endosperma em função do desenvolvimento plantular. Alves \& Dematê (1987) referem-se ao haustório como um órgão de sucção com função semelhante ao escutelo do milho, que é

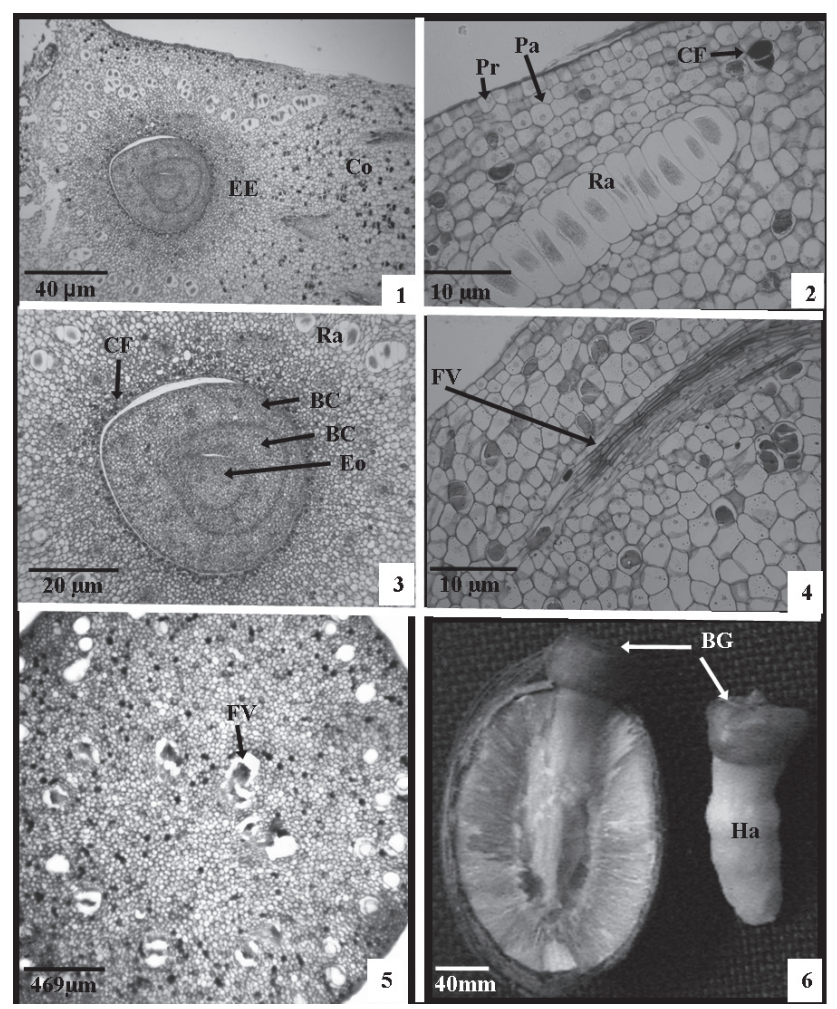

Figura 1. Embrião de Oenocarpus minor Mart. 1. Corte longitudinal do eixo embrionário. 2. Corte longitudinal do cotilédone. 3. Maior aumento da figura 1. 4. Feixe vascular no cotilédone em corte longitudinal. 5. Feixe vascular em corte transversal. 6. Fase inicial da germinação. $\mathrm{BC}=$ bainha cotiledonar; $\mathrm{BG}$ = botão germinativo; $\mathrm{Co}=$ cotilédone $\mathrm{CF}=$ composto fenólico; $\mathrm{EE}=$ eixo embrionário; $\mathrm{Eo}=$ eofilo; $\mathrm{FV}=$ feixe vascular; Há = haustório; $\mathrm{Pa}=$ parênquima; $\mathrm{PR}=$ protoderme; $\mathrm{Ra}=$ ráfide. 
tido por muitos estudiosos como o verdadeiro cotilédone, pois tem a função de dissolver e absorver o endosperma. Processo germinativo - A semente de O. minor germinou após sete dias da semeadura, com $96 \%$ de germinação. Dados semelhantes com germinação para a mesma espécie foram obtidos por Silva et al. (2006) e Silva et al. (2007). O início da germinação se dá pelo alongamento e diferenciação das células parenquimáticas da região proximal do cotilédone, resultando em uma expansão na zona periférica, de forma cilíndrica, formando o botão germinativo com aspecto cônico (Fig. 1.6).

Aos 14 dias após a semeadura, é emitida a raiz primária a qual servirá de sustentação para a plântula. Esta apresenta forma cilíndrica de cor amarelo-pálida (Fig. 2.1). A epiderme é espessada com células quadradas e paredes delgadas. $\mathrm{O}$ córtex possui camadas de células esclerenquimáticas, seguida de camadas de parênquima (Fig. 2.2-3). A endoderme é conspícua (Fig. 2.4). O cilindro vascular é delimitado por um periciclo unisseriado. O sistema vascular constitui-se de feixes dispostos alternadamente (Fig. 2.4). Para Esau (1977), esta disposição dos feixes é muito freqüente em monocotiledônea, classificando-a do tipo poliarca. A medula é esclerenquimática.

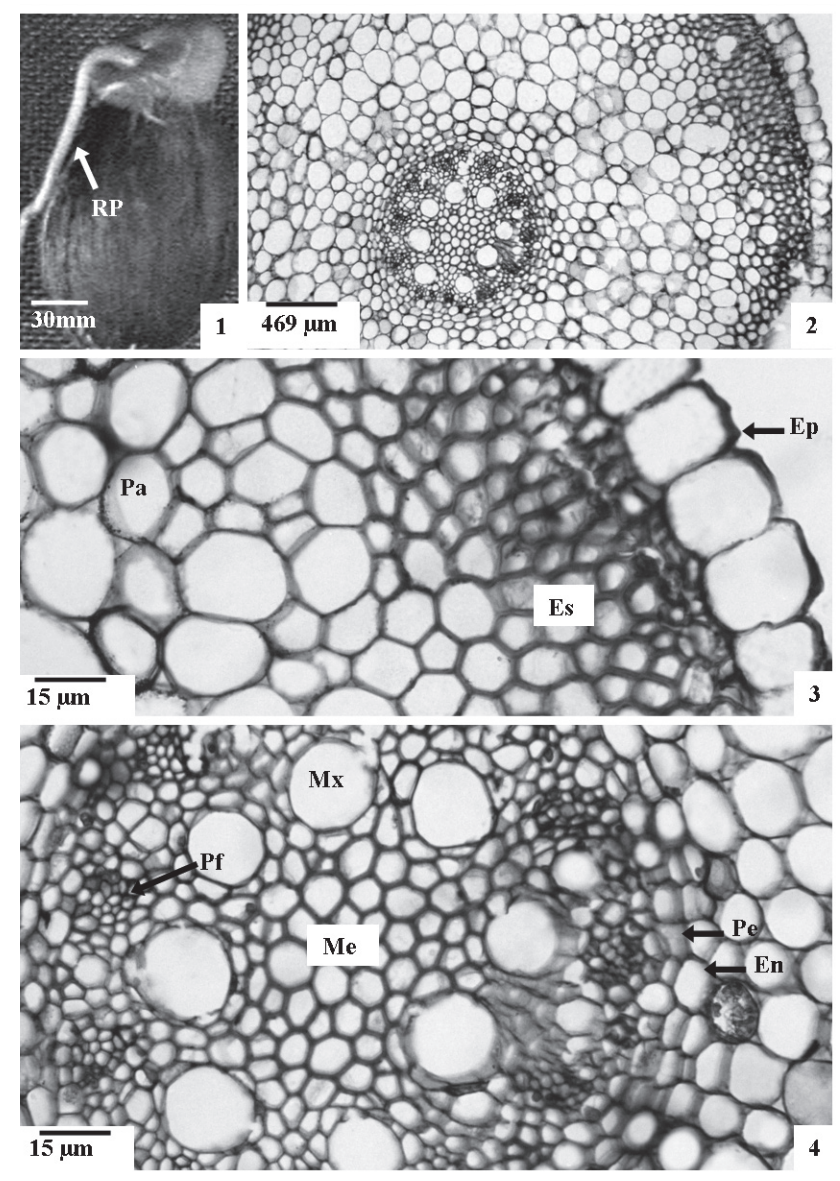

Figura 2. Raiz primária de Oenocarpus minor Mart. 1. Emissão da raiz. 2. Aspecto geral da raiz em secção transversal. 3. Epiderme e córtex. 4. Cilindro vascular. $\mathrm{En}=$ endoderme; $\mathrm{Ep}=$ epiderme; $\mathrm{Es}=$ esclereide $; \mathrm{Me}=$ medula; $\mathrm{Mx}=$ metaxilema $; \mathrm{Pa}=$ parênquima $; \mathrm{PE}=$ periciclo $; \mathrm{PF}=$ protofloema $; \mathrm{RP}$ = raiz primária.
Aos 21 dias é emitido o primeiro primórdio foliar que corresponde à primeira bainha cotiledonar, apresentando forma cilíndrica, afunilando-se em direção ao ápice rígido e pontiagudo o que facilita o deslocamento pelo substrato, medindo em média 1,6 mm de comprimento (Fig. 3.1).

A bainha cotiledonar possui epiderme uniestratificada e espessa, com células papiliforme na face adaxial e retangular na face abaxial com paredes delgadas e núcleos evidentes. O mesofilo compreende feixes procambiais circundado por braquiesclereídes, intercalando-se com células parenquimáticas amplas e idioblastos com conteúdo fenólico (Fig. 3.2). Por fim aos 35 dias, com a primeira bainha cotiledonar mais desenvolvida, medindo cerca de $11 \mathrm{~mm}$ de comprimento, é emitido o segundo primórdio foliar ou segunda bainha cotiledonar, semelhante à primeira com cerca de $3 \mathrm{~mm}$ de comprimento (Fig. 3.3-4), ocorrendo a emergência da plântula acima do substrato. Neste estádio, o terceiro primórdio foliar, ainda em formação é constituído de tecido fundamental, região originária do eófilo (Fig. 3.4).

A porção distal do embrião (região haustorial) aumenta progressivamente de tamanho durante o desenvolvimento germinativo e simultaneamente, o endosperma do cotilédone reduz a sua espessura com o desenvolvimento plantular (Fig. 3.3).

O tipo de germinação de $O$. minor é adjacente ligular. Conforme classificação de Tomlinson (1990), há três tipos de germinação em sementes de palmeiras: remota tubular, remota ligular e adjacente ligular. Este último tipo caracteriza-se pelo não alongamento do pecíolo cotiledonar, que conseqüentemente desenvolve-se adjacente à semente e ao mesmo tempo a formação da lígula (Fig. 3.1, 3.3) que ocorre ao redor do eixo embrionário, permanecendo durante todo o processo germinativo. Para Tomlinson (1990), esta estrutura pode estar presente ou ausente em algumas espécies de palmeiras, sendo visível somente em folhas novas, desorganizando-se com a maturação da folha. A semente de Euterpe precatoria também é classificada como adjacente ligular, e o pecíolo cotiledonar cessa seu alongamento quando o eixo embrionário emerge da semente fazendo com que a plântula se desenvolva próximo à mesma (Aguiar \& Mendonça 2002).

Os caracteres anatômicos do embrião e das fases iniciais da germinação de Oenocarpus minor Mart., descritos neste trabalho, mostram dados importantes para a melhor compreensão do processo germinativo das monocotiledôneas, em especial das palmeiras, bem como fornece informações para futuros estudos de propagação e domesticação da espécie estudada.

\section{Agradecimentos}

À Universidade Federal do Amazonas (UFAM), em especial ao Laboratório de Botânica Agroflorestal (LABAF) pelo apoio logístico e ao Conselho nacional Científico e Tecnológico $(\mathrm{CNPq})$ pelas bolsas concedidas. 

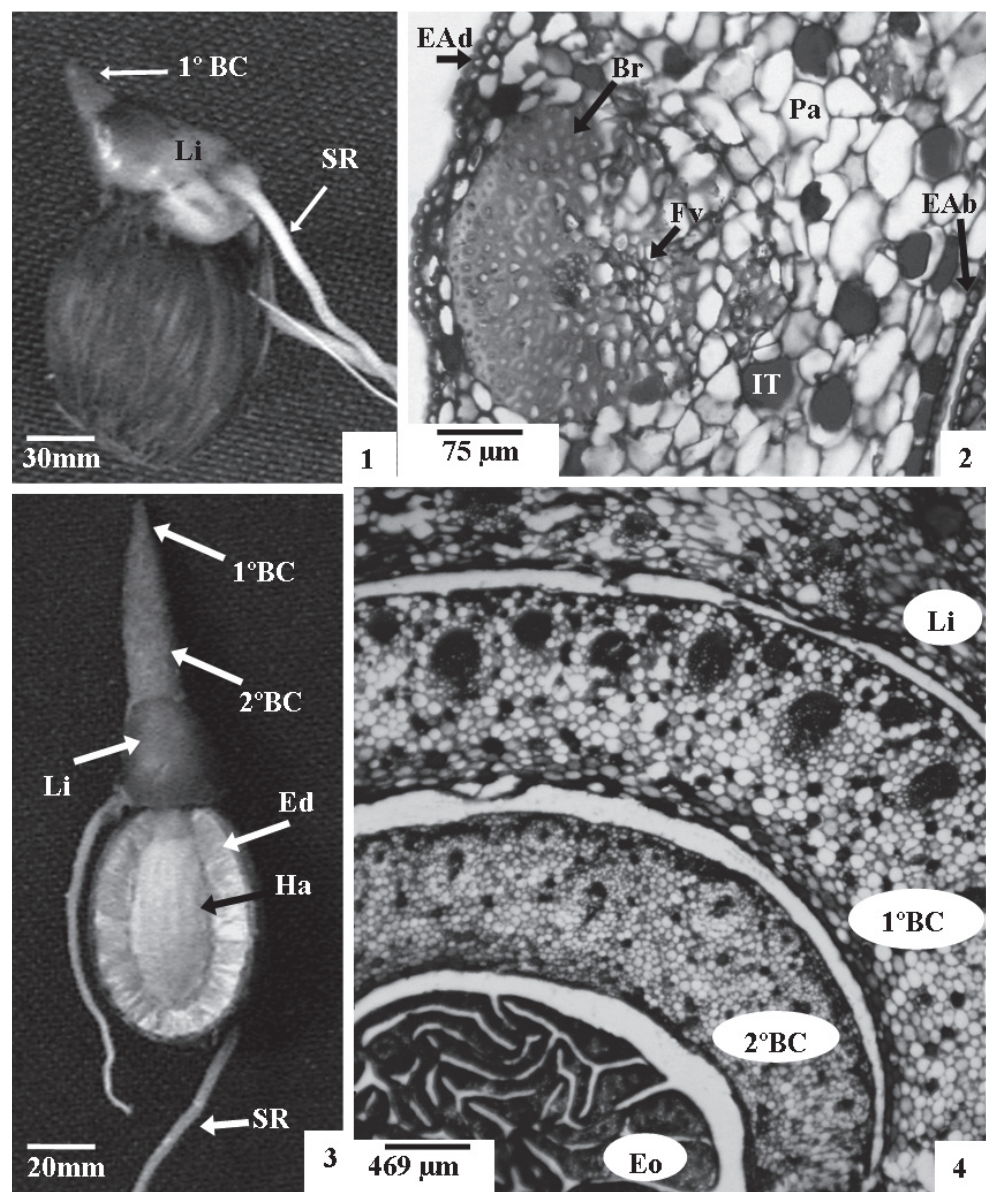

Figura 3. Estruturas da plântula de Oenocarpus minor Mart. 1. Emissão da primeira bainha. 2. Secção transversal da $1^{a}$ bainha cotiledonar. 3. Emissão da segunda bainha. 4. Secção transversal dos primórdios foliares. $1^{\circ} \mathrm{BC}=$ primeira bainha cotiledonar; $2^{\circ} \mathrm{BC}=$ segunda bainha cotiledonar; $\mathrm{BR}=$ braquiesclereíde; $\mathrm{EAb}=$ epiderme abaxial; EAd = epiderme adaxial; $\mathrm{Ed}=$ endosperma; $\mathrm{Eo}=$ eófilo; $\mathrm{FV}=$ feixe vascular; Há = haustório; $\mathrm{IT}$ = idioblasto com tanino; $\mathrm{Li}=$ lígula; $\mathrm{Pa}=$ parênquima; $\mathrm{SR}=$ sistema radicular.

\section{Referências bibliográficas}

Aguiar, M.O. \& Mendonça, M.S. 2002. Aspectos morfo-anatômico do embrião de Euterpe precatoria Mart. durante o processo germinativo. Acta Botanica Brasilica 16: 241-249.

Aguiar, M.O. \& Mendonça, M.S. 2003. Morfo-anatomia da semente de Euterpe Precatoria Mart. (Palmae). Revista Brasileira de Sementes 25: $37-42$.

Alves, M.R.P. \& Dematê, M.E.S.P. 1987. Palmeiras características botânicas e evolução. Campinas, Fundação Cargill.

Araújo, M.G.P. \& Leitão, A.M.; Mendonça, M.S. 2000. Morfologia do fruto e da semente de inajá (Attalea maripa (Albl.) Mart.)-Palmae. Revista Brasileira de Sementes 22: 31-38.

Balick, M.J. 1986. Systematics and Economic botany of the OenocarpusJessenia (Palmae) Complex. Advances in Economic Botany 3: 1-140.

Balick, M.J. 1992. Jesenia y Oenocarpus: palmas aceiteras neotropicales dignas de ser domesticadas. Roma, Organizacion de las Naciones Unidas para la Agricultura y la Alimentación.

Barcelar-Lima, C.G.; Mendonça, M.S.; Barbosa, T.C.T.S. 2006. Morfologia Floral de uma População de Tucumã, Astrocaryum aculeatum G. Mey. (Arecaceae) na Amazônia Central. Acta Amazonica 36: 407-412.

Belin-Depoux, M. \& Queiroz, M.H. 1988. Contribuição ao Estudo Ontogenético das Palmeiras. Alguns Aspectos da Germinação de Euterpe edulis. Mart. Pp. 211-213. In: Anais do I Encontro Nacional de Pesquisadores em Palmito. Curitiba 1988. Curitiba, Embrapa, CNPF.

Callegari-Jacques, S.M. 2003. Bioestatística. Princípios e aplicações. Porto Alegre, Artmed.
Demason, D.A. 1988. Embryo structure and storage reserve histochemistry in the palm Washingtonia filifera. America Journal of Botany 75 : 330-337.

Esau, K. 1977. Anatomy of seed plants. New York, John Wiley \& Sons.

Gabe, M. 1968. Techniques histologiques. Paris, Masson \& Cie.

Ginieis, P. C. 1956. Considérations générales sur la morphologie et l'anatomie des embryons palmiers. Bulletin du Muséum 2: 550-554.

Kraus, J. E. \& Arduin, M. 1997. Manual básico de métodos em morfologia vegetal. Rio de Janeiro, Edur.

Luz, P.B. Pimenta, R.S.; Unger, P.; Pizetta, C.; Castro, A. \& Pivetta, K.F.L. 2008. Germinação de sementes de Dypsis decaryi (Jum.) Beentje \& J. Dransf. (Arecaceae). Ciência e Agrotecnologia 32: 1461-1466.

Marcus, J. \& Banks, K. 1999. A practical guide to germinating palm seeds. Principes 1: 1-4.

Martin, A.C. 1946. The comparative internal mophology of seeds. The American Midland naturalist, Indiana 36: 513-660.

Mendonça, M.S. \& Araújo, M.G.P. 1999. A semente de bacaba (Oenocarpus bacaba Mart.-ARECACEAE); aspectos morfológicos. Revista Brasileira de Sementes 21: 122-124.

Mendonça, M.S.; Oliveira, A.B.; Araújo, M.G.P. \& Araújo, L.M. 2008. Morfo-anatomia do fruto e semente e Oenocarpus minor Mart. (ARECACEAE). Revista Brasileira de Sementes 30: 90-95.

O’Brien, T.P. \& Mccully M.E. 1981. The study of structure principles and selected methods. Melbourn, Termarcarphi Pty.

Pantiño, J.C. 1986. Microtecnia vegetal. México, Trilha. 
Passos, M.A.B. \& Mendonça, M.S. 2006. Epiderme dos segmentos foliares de Mauritia flexuosa L. f. (Arecaceae) em três fases de desenvolvimento. Acta Amazonica 36: 431-436.

Pivetta, K.F.L.; Sarzi, I.; Estelittas, M. \& Beckmann-Cavalcante, M.Z. 2008. Tamanho do diásporo, substrato e temperatura na germinação de sementes de Archontophoenix cunninghamii (Arecaceae). Revista de Biologia e Ciências da Terra 8: 126-134.

Silva, B.M.S.; Cesarino, F.; Lima, J.D.; Pantoja, T.F. \& Môro, F.V. 2006. Germinação de sementes e emergência de plântulas de Oenocarpus minor Mart. (ARECACEAE). Revista Brasileira de Fruticultura 28: 289-292.
Silva, B.M.S.; Cesarino, F. \& Pantoja, T.F. 2007. Emergência de plântulas de Oenocarpus minor Mart. em diferentes profundidades de semeadura. Revista Brasileira de Agroecologia 2: 1329-1332.

Sugimura, Y. \& Murakami, T. 1990. Structure and function of the haustorium in germinating Coconut palm seed. Japan Agricultural Research Quarterly 24: 1-14.

Tomlinson, P. B. 1990. The structural biology of palms. Principes 4: 56-63.

Uhl, N. W. \& Dransfield, J. 1987. Genera Palmarum: a classification of palms based on the work of Harold E. Moore, Jr. Lawrence, Allen Press. 